\title{
Diálogos entre bioética e saúde global: análise de usuários e usos de parques urbanos como indicadores éticos na promoção de bem-estar
}

\author{
Dialogues between bioethics and global health: \\ analysis of users and uses of urban parks as ethical \\ indicators in the promotion of wellbeing
}

\author{
Marta Luciane Fischer ${ }^{[1]}$ \\ Valquíria Elita Renk ${ }^{[I]}$ \\ Ana Maria Moser ${ }^{[\mathrm{III}]}$ \\ Natalia Aline Soares Artigas ${ }^{[\mathrm{IV}]}$
}

\begin{abstract}
Resumo
Embora as áreas verdes urbanas levem a benefícios biopsicossociais, a inserção em ambientes estigmatizados pode gerar vulnerabilidades. Este texto objetivou caracterizar os usuários e usos do passeio público de Curitiba por meio de pesquisa quantitativa da percepção e de condutas dos visitantes. Os resultados atestaram que o Parque está atrelado a referenciais emocionais, contudo a identificação de riscos tem conduzido a substituição por parques mais modernos. Famílias ainda frequentam o parque usufruindo dos animais para interação, no entanto essa satisfação as impede de perceber questões éticas. 0 conflito entre a importância do espaço para o cidadão e as vulnerabilidades sociais e dos animais conclama pela intervenção da bioética ambiental na intermediação do diálogo com a saúde global visando subsidiar o estabelecimento de uma solução consensual e justa para todos.

Palavras-chave: bioética ambiental; biofilia; ética animal; gentrificação; passeio público.
\end{abstract}

\begin{abstract}
Although green urban areas provide biopsychosocial benefits, insertions in stigmatized environments can generate vulnerabilities. We aimed to characterize the users and uses of the Passeio Público park in Curitiba through a quantitative survey of visitors' perceptions and behaviors. The results show that the park is associated with emotional references, yet the identification of risks has made it be replaced by parks that are more modern. Families still visit the park, interacting with its animals, but their satisfaction prevents them from perceiving ethical issues. The conflict between the importance of the environment to the citizen and social as well as animal vulnerabilities calls for the intervention of Environmental Bioethics to mediate the dialogue with Global Health, with the aim of subsidizing the establishment of a consensual and just solution.
\end{abstract}

Keywords: environmental bioethics; biophilia; animal ethics; gentrification; park. 


\section{Introdução}

A bioética ambiental dialoga com a saúde global ao interceder na resolução de impactos locais e globais decorrentes da tecnologia, capazes de prejudicar a saúde em uma escala biopsicossocial de pessoas, dos animais e do ambiente (Fortes e Ribeiro, 2014 e Fischer et al., 2017a). A interação ambiente/saúde compõe um campo da Saúde Pública (Brasil, 1999) que objetiva contribuir, por meio das Vigilâncias e Atenção Primária Ambiental (Augusto, 2003 e Silva e Loreto, 2011), na promoção de sustentabilidade ambiental, equidade social e atenuação de impactos decorrentes da urbanização e industrialização (Golveia, 1999). Dentre as intervenções para promoção de saúde e prevenção de doenças, inserem-se os parques urbanos, os quais, além de melhorarem a drenagem, umidificação e despoluição e atenuarem os excessivos estímulos visuais, sonoros, odoríferos e térmicos (Dorigo e Ferreira, 2015), promovem o bem-estar físico, mental e social, ao disponibilizarem refúgios para o cidadão que busca autorrestauração. Os parques urbanos constituem-se de espaços de uso público destinados à recreação, capazes de inserir elementos de conservação em uma estrutura morfológica autossuficiente (Macedo e Sakata, 2010). Os benefícios dos espaços verdes urbanos encontram respaldo na teoria da biofilia (Kerllet e Wilson, 1993) que preconiza que a saúde biopsicossocial dos humanos é condicionada à interação com elementos naturais. Contudo a qualidade da saúde tem sido comprometida em decorrência do rápido e intenso desenvolvimento tecnológico que paulatinamente distancia o homem da natureza. Assim, faz-se urgente a substituição de paradigmas éticos antropocêntricos por valores bio/ecocêntricos, no intuito de restabelecer um convívio harmônico com a natureza (Fischer et al., 2017a). Segundo Potter (2016), há uma relação direta entre a saúde humana, animal e ambiental, logo a bioética deve intermediar a sustentabilidade com menor impacto possível, a fim de que todas as espécies, de todas as gerações, tenham a oportunidade de desfrutar de um ambiente saudável.

A paisagem urbana representa a materialização de um instante da sociedade, logo precisa ser dimensionada em cada momento político, econômico e social (Santos, 1988). 0 estudo da percepção da população sobre as áreas verdes urbanas tem indicado transposição da concepção de função estética e de lazer para aplicação dos conceitos de sustentabilidade, conservação e qualidade de vida (Tuan, 1980; Ferreira, 2005 e Fischer et al., 2017b). Frequentadores do Jardim Botânico do Rio de Janeiro relataram sentir conforto, satisfação e bem-estar ao admirar, em silêncio, o verde e os animais (Ferreira, 2005).

Os parques urbanos estabeleceram-se no século XIX na Europa, com função utilitarista que incorporava condutas higiênicas na vida social e na saúde pública, com a drenagem dos rios, mitigação de impactos da urbanização e incipiência de saneamento básico. Igualmente contribuíram para refrescar os ares, servindo como espaços de lazer e recomposição das energias (Loboda e Angelis, 2005). Nesse contexto, destacam-se o Hide Park, em Londres, o Bois de Bologne, em Paris e o Central Park em Nova York (Pelegrini, 2006). Os parques urbanos passaram a compor uma nova perspectiva dos planos de urbanização, concomitantemente incorporando significados (Carlos, 2007), segundo a qual 
o cidadão assume a postura de voyeur que percorre a cidade, cria trajetórias, aciona memórias e sentidos (Certeau, 1996). As áreas históricas precisam ser inseridas nas políticas das cidades com planejamento do uso dos espaços em consonância com necessidades e anseios da população, para que não se tornem decadentes e em conflito com questões éticas emergentes. A renovação dos espaços deve oportunizar aos habitantes a interação com áreas verdes (Brun et al., 2010), consequentemente a promoção do bem-estar do ponto de vista ético, ambiental e de plenitude urbana, associando-se a indicadores de bem-estar individual, ambiental e econômico. As práticas sustentáveis ampliadas visam à promoção de cidades verdes, eficientes e solidárias, as quais, atreladas à educação ambiental, devem propiciar manutenção, conservação e segurança. Considerando que o espaço é a fusão entre a sociedade e a paisagem, é necessário compreender as ações e os interesses das pessoas, das instituições, das empresas e do meio ecológico, assim como dos paradigmas éticos envolvidos nessa relação (Rodrigues, 1999). Logo, justifica-se a análise multidisciplinar do espaço utilizado por todos os seres vivos envolvidos na dinâmica da Ecologia Urbana.

Curitiba é reconhecida pelos seus parques, os quais fazem parte dos planos diretores desde a década de 1970, inicialmente vinculados à contenção de enchentes dos rios Barigui, São Lourenço e Iguaçu e, posteriormente, nos anos de 1990, vinculados à revitalização de áreas degradadas, como o Jardim Botânico, Tingui, Tanguá e Pedreiras. Desde então, Curitiba passou a ser referida, no city marketing, como capital ecológica do Brasil (Garcia, 1997 e Sanchez, 2013).
Nesse cenário, destaca-se o Passeio Público, o primeiro parque e zoológico da cidade, inaugurado em 1886, localizado no anel central da cidade. Embora esse parque tenha um forte contexto histórico e emotivo para os curitibanos, está inserido em uma situação que demanda revitalização, conduzindo à pergunta norteadora do presente estudo de qual é a percepção e utilização do Passeio Público como espaço urbano e se há convergência de interesses entre a promoção de recreação e o seu potencial na geração de vulnerabilidades.

Justifica-se a realização desta pesquisa, uma vez que a revitalização deve levar em consideração características dos usuários e os usos do espaço como promotores de saúde global. Além disso, o parque ainda expõe dezenas de animais mesmo diante da questionável capacidade de promoção de graus satisfatórios de bem-estar animal (BEA), argumentos que compõem as pautas de discussão das atribuições da instituição contrapondo com as demandas da sociedade em conhecer e interagir com espécies selvagens (Fischer et al., 2017c).

0 presente estudo teve como hipóteses: a) o Passeio Público está inserido no contexto cultural, histórico e emocional dos curitibanos, contudo, devido ao potencial gerador de vulnerabilidades, foi substituído por parques mais modernos; b) a população apresenta uma relação com o Passeio Público influenciada pela identificação com concepções ambientais e éticas condicionadas a idade, gênero e área profissional; c) os usuários do Passeio Público satisfazem-se com os animais e não identificam conflitos éticos.

A análise dos resultados foi norteada pela ideia central de que a gestão do parque deve ser inserida em debates multidisciplinares 
e democráticos diante das novas demandas sociais atreladas à ética animal e ambiental. Consequentemente, espera-se que mudanças na representação da natureza e dos valores éticos associados ao uso do espaço verde devam estimular a reflexão do papel desses ambientes. Logo, inseriu-se a questão na perspectiva da bioética ambiental cuja intermediação visa à equalização dos argumentos dos atores envolvidos na questão ética, visando mitigar vulnerabilidades tanto do cidadão, que tem o direito de usufruir de espaços públicos que supram suas demandas biológicas de convívio com a natureza, quanto dos animais, que são expostos em condições promotoras de baixos graus de BEA. Assim, objetivou-se caracterizar os usuários e os usos do Passeio Público como indicadores éticos na promoção de bem-estar da população.

\section{Métodos}

\section{Estudo de caso: o Passeio Público}

O Passeio Público, tombado em 1999 como Patrimônio Cultural, foi construído no final do século XIX, visando saúde e higiene urbana (Boletim, 2001). Inspirado nos parques europeus, cujo portão em estilo art nouveau assemelha-se aos portões do Cemitiére des Chiens de Paris (ibid.), possui uma área de $69.285 \mathrm{~m}^{2}$ e está localizado na área central. 0 parque é constituído por alamedas de árvores de diversas partes do mundo, lagos artificiais, pontes, grutas, rochedos, cascatas, ilhas, um espelho de água formado pelo rio Belém, diversos exemplares da fauna e restaurantes (ibid.). Originalmente era considerado um espaço suntuoso de natureza cosmopolita, destinado ao lazer, em meio às mansões do Alto da Glória, atraindo multidões aos finais de semana. A partir de 1932, operou por 50 anos como o único zoológico de Curitiba, com a introdução de animais de pequeno, porte como pavões, macacos e aves, e de grande porte, como chimpanzés, onças, leões, jacarés e girafas, sendo os de grande porte, a partir de 1982, transferidos para o novo Zoológico de Curitiba, no Parque Regional do Iguaçu (ibid.). Atualmente, o parque encontra-se em uma área decadente, cujo entorno agrega mendicância, prostituição, uso de drogas e furtos. A desvalorização comercial dos imóveis levou a serem utilizados como cortiços ou hotéis de alta rotatividade, resultando em problema social, áreas carregadas de estigmas, marginalizadas e com valor simbólico negativo (Vale e Maciel, 2016). Considerado como o Central Park de Curitiba, já passou por inúmeras interferências e processos de revitalização, objetivando oferecer segurança e conforto aos seus usuários, agregando novas áreas de lazer como os pedalinhos, pista de caminhada, playground e mesas de xadrez.

\section{0 passeio público sob a perspectiva popular}

\section{Instrumento}

Para avaliação da percepção da população de Curitiba a respeito do Passeio Público, foi elaborado um instrumento contendo 7 questões abertas de caracterização (idade, profissão, formação, gênero, bairro de moradia, tempo de residência em Curitiba e quais parques frequenta); 10 questões abertas sobre a percepção do Passeio Público (frequência e motivos de visitas, pontos positivos e negativos, relação 
e opinião sobre os animais, relato de um caso vivenciado e relação com o parque) e 17 assertivas para serem pontuadas (1-9) de acordo com à aderência a desfechos vinculados a diferentes atitudes diante de questões ambientais e identificação com percepções do ambiente adaptadas das escalas propostas por Guillén (1991) e Sauvé (1996), respectivamente, e valoração atribuída ao animal segundo diferentes perspectivas éticas (Quadro 1).

\section{Participantes}

0 acesso ao participante $(\mathrm{N}=534)$ deu-se pela hospedagem on-line do instrumento no software Qualtrics, o qual foi mantido por 18 meses (novembro de 2014 a abril de 2016) e divulgado pela rede de contatos dos pesquisadores e por acesso a múltiplos grupos disponíveis em redes sociais. Concomitantemente, os visitantes do parque foram abordados e foi aplicado o mesmo questionário; suas respostas foram registradas on-line. $\mathrm{A}$ análise dos dados correspondeu aos questionários completos $(\mathrm{N}=507)$. Os respondentes possuíam idade média de $29,5 \pm 12,3$ anos (507; 18-85), 68\% eram mulheres e $32 \%$ homens; destes, $53 \%$ nasceu em Curitiba. 0 tempo médio de residência dos não nascidos era de $21 \pm 13,8$ anos (168; 0-67), e eles eram originários de 19 localidades. Os moradores de Curitiba foram originários de $77 \%$ bairros da capital, com predomínio do Centro (7,8\%). Os respondentes exerciam 51 ocupações diferentes, predominando estudantes $(27 \%)$ e professores $(11,5 \%) ; 52,6 \%$ eram de áreas profissionais de biológicas e ambientais.

Figura 1 - Localização do Passeio Público. Imagem Satélite e no mapa do Brasil, Paraná e Curitiba

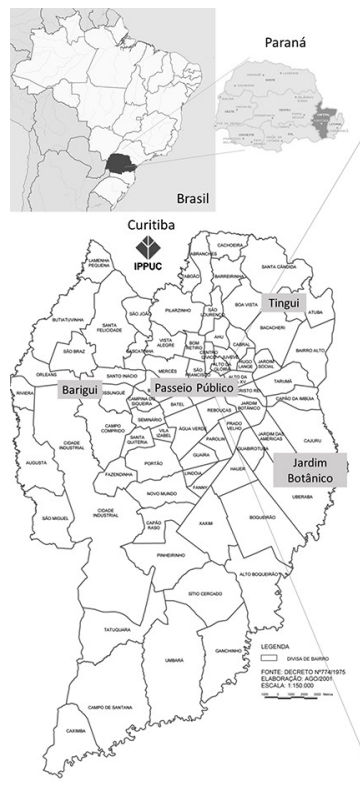

Fonte: IPPUC e Google maps.

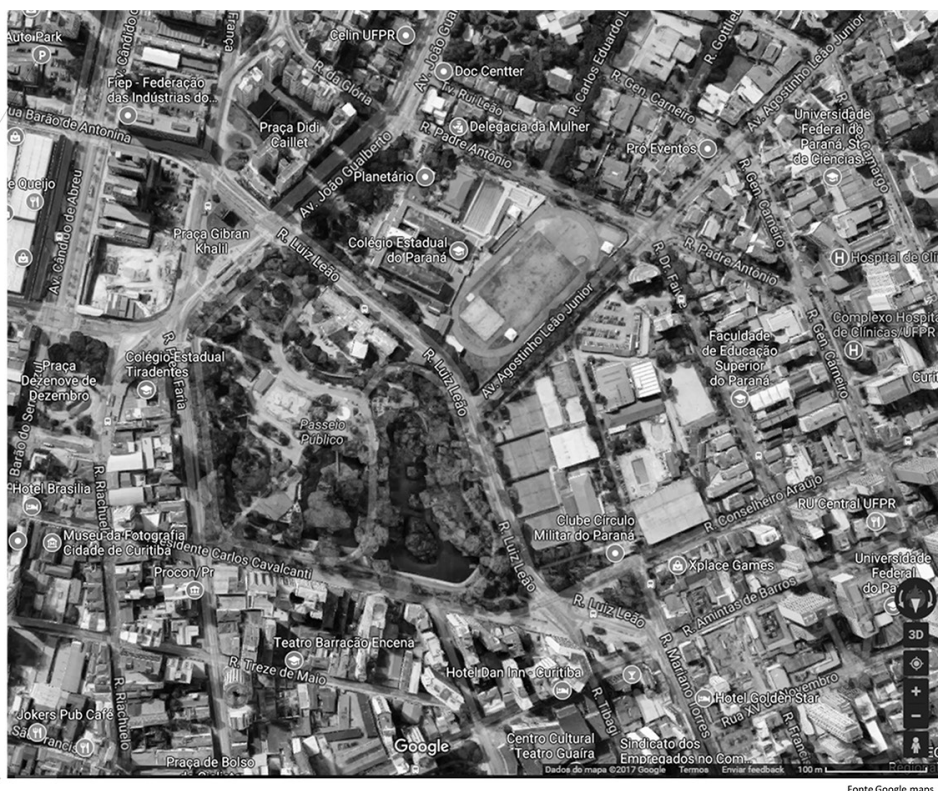

Fonte Google.maps 


\section{Análise dos dados}

As respostas abertas foram categorizadas pela análise de conteúdo semântico de Bardin (2011). Seus reagrupamentos resultaram nas categorias: a) pontos positivos $=$ animais, diversidade de atividades, entrada e banheiro gratuitos, diversão para crianças, lazer e eventos, estética, contexto histórico, memória, localização, natureza, relaxamento e segurança; b) pontos negativos = maus-tratos aos animais, recintos pequenos, falta de informações da fauna e flora e educação ambiental, fiscalização, frequentadores, falta de infraestrutura/manutenção, localização, poluição sonora e visual, falta de lazer, de lanchonetes e de estacionamento; c) relato de caso vivenciado $=$ constrangimento, infância e família, animais (acasalando, mortos, soltos, experiências pessoais, agressão pelo público), eventos, estudos e trabalho, lamentação, contato com a natureza; d) relação com Passeio = crítica, elogio, indiferença, desprezo, opinião pessoal e sentimento, resgate impressões do passado, proposta de solução, lamentação, revolta e saudosismo. A adesão às assertivas foram analisadas, considerando como variáveis idade, gênero e área de atuação profissional.

\section{Avaliação do visitante}

0 comportamento dos visitantes foi avaliado em três domingos, durante a manhã e a tarde, sendo registradas as atividades (descansar, exercícios, comer, pedalinho e ver animais) exibidas por jovens e adultos do sexo masculino e feminino, casal, família e grupos. Para a caracterização das condutas com relação aos animais, foram registrados os comportamentos dos visitantes que se aproximaram dos recintos, durante 77h de observação, distribuídas em 21 dias (abril a julho de 2015), por quatro observadores. Cada observador permaneceu por 30 minutos diante dos recintos das aves, 30 minutos nos mamíferos, 30 minutos nos répteis e 30 minutos nos peixes.

Os visitantes foram categorizados de acordo com: a) faixa etária = crianças (4-13 anos), adolescentes (14-21 anos), adultos (2260 anos) e idosos (mais de 60 anos); b) grupo = pessoas desacompanhadas, família, grupo de adultos e grupo de crianças; c) atitudes = positivas, negativas e ambas; d) reação $=$ comentários, tomada de fotografias, chamada de atenção, interação com o animal, indiferença às placas e não leitura delas; d) condutas = desinteresse, curiosidade, admiração, agressividade (jogar objetos, balançar/subir na grade, depreciar verbalmente, gritar com o animal, imitar o animal de modo ameaçador), interação (estender a mão, oferecer objeto, oferecer ou jogar alimento, chamar o animal por apelido ou nome, acenar, imitar o animal de maneira interativa, rir do animal) e medo (recuar, olhar com temor, alertar verbalmente sobre perigo). Os comentários foram categorizados em admiração, elogios direcionados aos animais, lamentação, comparação, depreciação, percepção ética de questões relacionadas ou não com a natureza.

Foram entrevistados cinco trabalhadores do parque quanto à caracterização do trabalho (tempo, descrição, dificuldades e aspectos positivos), do parque (problemas ambientais e sociais e sugestões para melhoria) e do visitante (comportamentos e dias de maiores ocorrências de situações adversas), acrescentando a opinião de uma prostituta e de um morador de rua. 


\section{Procedimentos estatísticos e legais}

A homogeneidade da frequência das respostas dos respondentes com relação aos parques urbanos e ao Passeio Público, assim como as variáveis resultantes da categorização das respostas abertas, foi testada através do teste não paramétrico Qui-quadrado. Para análise da pontuação média atribuída às assertivas com diferentes desfechos, os valores foram comparados entre cada uma das três abordagens e entre as variáveis, utilizando o teste Anova. Em todos os testes, foi considerada como hipótese nula a existência de uniformidade da amostra em um nível de significância de 95\% e erro de $5 \%$. Para atender aos princípios éticos, o estudo foi realizado em conformidade com a declaração Helsinque e resoluções CNS 466/12 e 510/2016, respeitando a integridade e o anonimato dos entrevistados, das pessoas observadas no parque, assim como o tratamento, análise e preservação dos dados. 0 projeto detém aprovação do CEP/PUCPR (nº 852.493/2014).

\section{Resultados}

\section{Relação com parques urbanos}

Os respondentes on-line (64\% jovens, 30,1\% adultos e 1,9\% idosos) relataram frequentar 21 parques e 16 praças de Curitiba e 7 de outras cidades, predominando Barigui (28,7\%), Jardim Botânico (22,8\%) e Tanguá $(11,6 \%)\left(\chi_{(10)}^{2}=602\right.$, $\mathrm{P}<0,0001)$. A maioria dos entrevistados listou até três parques (1: 37,9\%; 2:29,4\%, 3:16,1\% - $\left.\chi_{(7)}^{2}=719 ; \mathrm{P}<0,0001\right)$. As atividades mais frequentes foram lazer (54\%) e esportes (32\%), quando comparadas com contato com natureza e relaxamento $(8,5 \%)$, estudos e trabalho $(2,86 \%)$, arte $(0,95 \%)$, eventos $(0,95 \%)$ ou transitar $(0,48 \%)\left(\chi_{(8)}^{2}=753, \mathrm{P}<0,0001\right)$.

\section{Relação com Passeio Público}

A maioria dos respondentes $(93,4 \%)$ conhecia - Passeio Público, contudo apenas $12 \%$ visitava-o com frequência. Os motivos relatados foram lazer (66\%), animais (24,6\%), esporte $(4,5 \%)$, educação $(3,5 \%)$ e outras atividades $(1,34 \%)\left(\chi_{(4)}^{2}=561, P<0,0001\right)$; destes $99 \%$ dos idosos relataram o lazer. A visita condicionada ao zoológico foi citada por $24 \%$ dos adultos, $15 \%$ dos jovens e $1 \%$ dos idosos. Os pontos positivos foram relacionados, principalmente, à localização, aos animais e às atividades; e as queixas foram atreladas ao estado de conservação e aos frequentadores. Os respondentes não evidenciaram perceber claramente os conflitos decorrentes da manutenção dos animais para exposição, muitos dos quais alegaram boas condições e oportunidade de interação com a natureza (Figura 2).

\section{Relação do Passeio Público com valores ambientais e éticos}

A percepção do Passeio Público por 294 respondentes $(28,2 \%$ jovens, $25,5 \%$ adultos e $12 \%$ idosos) indicou identificação com atitudes realistas e emotivas, sendo a naturalista a menos frequente, contudo predominante em idosos e profissionais oriundos de áreas não biológicas. As mulheres mostraram predomínio da atitude emotiva e realista e os homens da utilitarista. A percepção do Parque como natureza foi a menos frequente como um todo, contudo mais predominante em homens e idosos. As mulheres e os profissionais das áreas biológicas/ambientais identificaram-se mais como um problema a ser resolvido. Enquanto idosos e profissionais de áreas não biológicas perceberam-no como recurso e biosfera. A valoração antropocêntrica e 


\section{Quadro 1 - Avaliação da percepção dos respondentes quanto à identificação com as assertivas com desfechos associados com diferentes atitudes e percepções ambientais e valoração dos animais conforme diferentes perspectivas éticas. O Passeio Público...}

\begin{tabular}{|c|c|c|}
\hline \multirow{5}{*}{ 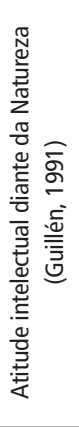 } & Naturalista & $\begin{array}{l}\text {...é um espaço que conserva o ambiente com elementos da natureza, como as plantas e os } \\
\text { animais. A natureza é boa, mas pode se vingar das açôes que são praticadas contra ela caso seja } \\
\text { maltratada. }\end{array}$ \\
\hline & Emotiva & $\begin{array}{l}\text {...é um lugar que desperta emoções que podem ser desde sensações agradáveis e prazerosas } \\
\text { ou mesmo pode despertar o medo e a insegurança. Sinto medo de andar em certos lugares do } \\
\text { parque e em alguns horários. }\end{array}$ \\
\hline & Utilitarista & $\begin{array}{l}\text {...é um espaço que pode ser usado pelas pessoas para lazer ou conforme seus interesses (como } \\
\text { curtir, namorar, andar, correr, trabalhar, visitar os animais e outros) desde que traga a felicidade. }\end{array}$ \\
\hline & Racionalista & $\begin{array}{l}\text {... apesar de ser um espaço de lazer que deve ser considerado em sua dimensão cultural, } \\
\text { biológica, de preservação das espécies e também é um ambiente de trabalho. }\end{array}$ \\
\hline & Realista & $\begin{array}{l}\text {...é o mais antigo parque urbano de Curitiba, é espaço de lazer, de trabalho e também abriga } \\
\text { animais, mas, é um espaço decadente que precisa ser revitalizado para ser seguro. }\end{array}$ \\
\hline \multirow{6}{*}{ 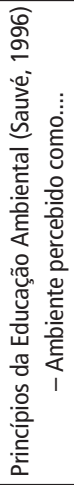 } & ...Natureza & $\begin{array}{l}\text {...é um lugar que posso contemplar e interagir com a natureza e me sinto integrado com o } \\
\text { natural. }\end{array}$ \\
\hline & ...Recurso & $\begin{array}{l}\text {...é um parque que mostra como são algumas espécies animais e vegetais. Os recursos naturais } \\
\text { devem ser usados para produzir coisas úteis e também reciclar o que for possível. }\end{array}$ \\
\hline & ...Problema & $\begin{array}{l}\text {... existem muitos problemas ambientais como a poluição, o lixo, a degradação, que são os } \\
\text { reflexos dos problemas da vida urbana. }\end{array}$ \\
\hline & ...Local para viver & $\begin{array}{l}\text {... podemos ter mais contato com a natureza e melhorar a nossa qualidade de vida. Nós temos } \\
\text { direito à qualidade de vida, mas, também somos responsáveis por um ambiente saudável. }\end{array}$ \\
\hline & ...Bioesfera & $\begin{array}{l}\text {...é um espaço que servir como espaço para a Educação Ambiental e conscientização da } \\
\text { importância de uma consciência planetária. }\end{array}$ \\
\hline & $\begin{array}{l}\text {...Projeto } \\
\text { comunitário }\end{array}$ & $\begin{array}{l}\text {...é um espaço que poderia ser assumido pelos moradores e visitantes na conservação e } \\
\text { preservação. Eu também poderia me envolver neste projeto, deixando -o agradável, seguro e } \\
\text { que atraísse novamente os moradores e visitante. }\end{array}$ \\
\hline \multirow{7}{*}{ 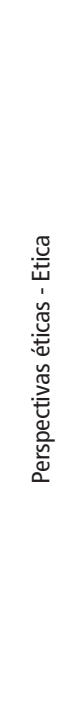 } & Antropocêntrica & $\begin{array}{l}\text { Não acho errado a presença de animais em parques urbanos como o passeio público, pois os } \\
\text { mesmos devem ser estruturados visando o bem-estar físico, social e psicológico das pessoas, } \\
\text { que são os cidadãos que pagam seus impostos e têm direito de um lugar seguro para se divertir } \\
\text { e descansar. }\end{array}$ \\
\hline & Utilitarista & $\begin{array}{l}\text { Não acho errado a presença de animais em parques urbanos como o passeio público, pois é } \\
\text { extremamente útil para as pessoas terem oportunidade de conhecer e interagir com animais } \\
\text { diferentes. }\end{array}$ \\
\hline & Bem-estarista & $\begin{array}{l}\text { Não acho errado a presença de animais em parques urbanos como o passeio público, desde que } \\
\text { eles estejam em boas condições de manutenção e manejo, tenham comida e água e estejam } \\
\text { protegidos e tenha assistência médica. }\end{array}$ \\
\hline & Senciocêntrica & $\begin{array}{l}\text { Não acho errado a presença de animais em parques urbanos como o passeio público, desde } \\
\text { que não sejam animais que possuam capacidade de sofrerem por estarem confinados como os } \\
\text { grandes mamíferos. }\end{array}$ \\
\hline & Abolicionista & $\begin{array}{l}\text { Acho errado manter animais confinados em parques urbanos como o passeio público, pois o } \\
\text { cativeiro suprime a liberdade do animal que deveria estar livre na natureza vivendo a sua vida. }\end{array}$ \\
\hline & Biocêntrica & $\begin{array}{l}\text { Acho errado manter animais confinados em parques urbanos como o passeio público, pois todos } \\
\text { os seres vivos são dignos de respeito e consideração moral pelo seu próprio valor como ser vivo } \\
\text { e não pelo valor que tem para o homem. }\end{array}$ \\
\hline & Ecocêntrica & $\begin{array}{l}\text { Acho errado manter animais confinados em parques urbanos como o passeio público, pois as } \\
\text { espécies não podem viver isolada e fora do ambiente para o qual evoluiu. A vida é uma rede de } \\
\text { inter-relações entre todos os elementos do ecossistema. }\end{array}$ \\
\hline
\end{tabular}


utilitarista dos animais foi a menos frequente, porém predominante em homens e idosos. Profissionais de áreas não biológicas se identificaram com assertivas bem-estaristas e senciocêntricas e os jovens com as biocêntricas (Figura 3).

Figura 2 - Esquema dos resultados da percepção da população a respeito do Passeio Público com exemplos de relatos de caso e frases associadas

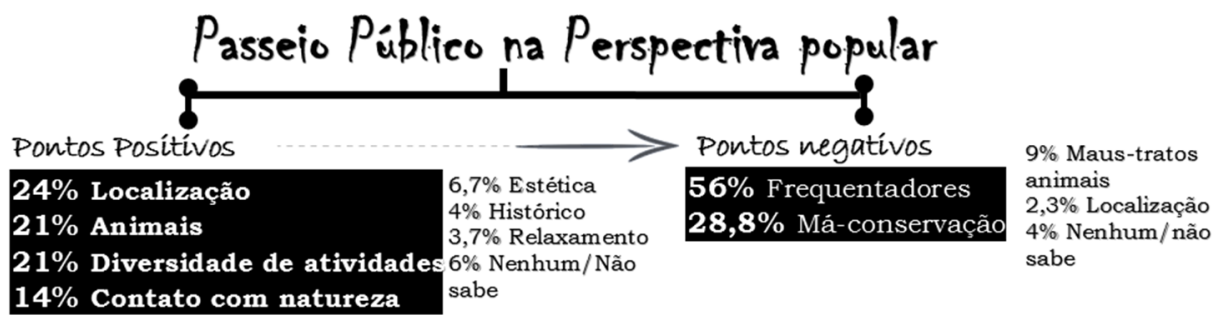
$14 \%$ Contato com natureza

\begin{tabular}{|c|c|c|}
\hline $\begin{array}{l}\text { 33\% Não sabe } \\
26 \% \text { Sim/Espaço/Público } \\
\text { 18\% Sim/Infraestrutura }\end{array}$ & $\begin{array}{l}\text { 13\% Discorda com a exposição } \\
9 \% \text { Estressados/Doentes } \\
6,6 \% \text { Nenhum } \\
3,8 \% \text { Bem cuidados }\end{array}$ & $\begin{array}{l}\mathbf{5 3} \% \text { Aves } \\
26,5 \% \text { Todos }\end{array}$ \\
\hline
\end{tabular}

$8,6 \%$ Peixes

$6,9 \%$ Macacos

$4 \%$ Cobras

$0,5 \%$ Quelônios

$0,5 \%$ Próximos do público

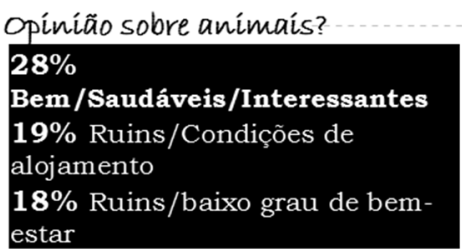

Quaís estão melhores?

$14 \%$ Discorda $11 \%$ Não sabe $6,8 \%$ Ruim/Educação $3,8 \%$ Bem cuidados

$42 \%$ Não Sabe
$15 \%$ Boa
alimentação

$12 \%$ Aves 7,85 Todos $5,7 \%$ Mamiferos $1,6 \%$ Peixes $3,6 \%$ Répteis estar

caso vivencíado no passeío?

$34 \%$ Não lembra

$20 \%$ Infância

17\% Animais
$11 \%$ Constrangimento

$4,2 \%$ Assalto

$3,6 \%$ Evento

$2,7 \%$ Natureza $8,2 \%$ Outro

"Fez parte da minha infância"

"Gosto de me sentir parte do Passeio Público"

"Centro de cidade não é local para exposição de animais, visto o fluxo de carros, poluição sonora entre outras"

"Um sentimento de carinho e de paz a distância, nas poucas vezes que vou lá me traz muita tranquilidade"

"Cortei minha relação com o passeio ainda criança por não concordar com as condições de vida dos animais lá expostos".

"Gostaria que o Passeio fosse somente uma área de lazer com maior segurança, sem animais presos"

\section{Relação com Passeío?}

\begin{tabular}{|c|c|c|}
\hline $\begin{array}{l}49 \% \\
\text { Positiva }\end{array}$ & $\begin{array}{l}41 \% \\
\text { Pessoal }\end{array}$ & $\begin{array}{l}37 \% \text { Bem-estar } \\
16 \% \text { Lamentação }\end{array}$ \\
\hline $19 \%$ Neutra & $20 \%$ Critica & $15 \%$ Indiferença \\
\hline $\begin{array}{l}18 \% \text { Negativa } \\
15 \% \text { Ambas }\end{array}$ & $\begin{array}{l}18 \% \text { Indiferen } \\
9,5 \% \text { Resgate } \\
6,8 \% \text { Solução } \\
6 \% \text { Elogio }\end{array}$ & $\begin{array}{l}\text { Iça } 9 \% \text { Desprezo } \\
8,4 \% \text { Saudosismo } \\
7,1 \% \text { Revolta } \\
6 \% \text { Factual } \\
2 \% \text { Sensações }\end{array}$ \\
\hline
\end{tabular}

"Quando ainda havia chipanzés, tive a oportunidade de chegar bem perto de uma fêmea. Trocamos carinhos e senti uma emoção sem igual. Mistura de alegria pela oportunidade e tristeza por ela estar enjaulada. Me marcou muito a percepção dela com nosso parentesco. Olhou minhas unhas e comparou com as dela, meus pelos com os dela e um olhar triste que me emociona até hoje só de lembrar"

*A homogeneidade da amostra de categoria foi testada através do teste do Qui-quadrado, sendo os valores significativamente maiores $(P<0,05)$ apresentados na caixa escura. 
Figura 3 - Pontuação média de concordância dos respondentes com as assertivas com desfechos vinculados à atitude diante da natureza, como percebem o ambiente e seu posicionamento ético diante da exposição dos animais

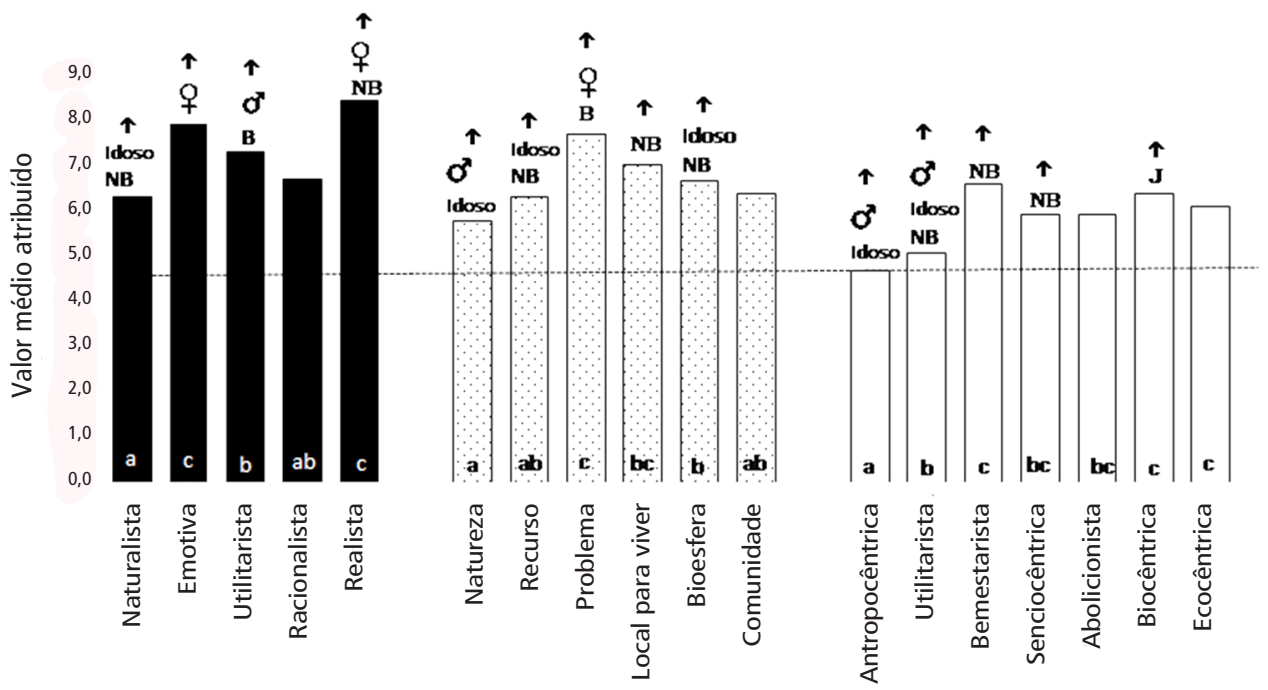

Em destaque, as variáveis significativamente predominantes em cada categoria (= $\delta$ Homem, $q=$ Mulher, Idoso, $\mathrm{J}=$ jovem; ocupação profissional da área biológica= B e não biológica= NB).

* Os valores de cada variável foram comparados dentro de cada categoria por meio do teste Anova e posteri de Tukey, sendo os valores significativamente $(\mathrm{P}<0,05)$ diferentes, acompanhados por letras distintas.

\section{Relação dos usuários do Parque com os animais}

Os 995 registros totalizaram 2281 visitantes ( $68 \%$ adultos, $25 \%$ crianças e $6 \%$ idosos) pertencentes a grupos médios de 2,4 $\pm 1,1$ (1-11), cujas reações foram majoritariamente positivas, compostas por comentários, tomadas de fotografias e chamadas de atenção. Houve mais comentários de admiração e elogios e comportamentos de surpresa, contemplação e curiosidade. Não houve diferenças nas proporções de atitudes positivas e negativas quando comparados os recintos de animais aquáticos, aves, mamíferos e répteis (Figura 4).

A entrevista com os trabalhadores congregou um funcionário público de 53 anos, com ensino superior e função de tratador; um policial de 49 anos com ensino básico, responsável pelo módulo da Polícia Militar; três comerciantes, sendo um vendedor ambulante de 69 anos, com ensino fundamental, um pipoqueiro de 51 anos, com ensino superior incompleto, e um gerente do restaurante de 45 anos com 
Figura 4 - Síntese do comportamento dos visitantes, exemplos de comentários proferidos diante dos recintos dos animais

e gráfico indicando frequência relativa de atividades realizadas durante um domingo pela manhã e à tarde por jovens, adultos, casais, famílias e grupos
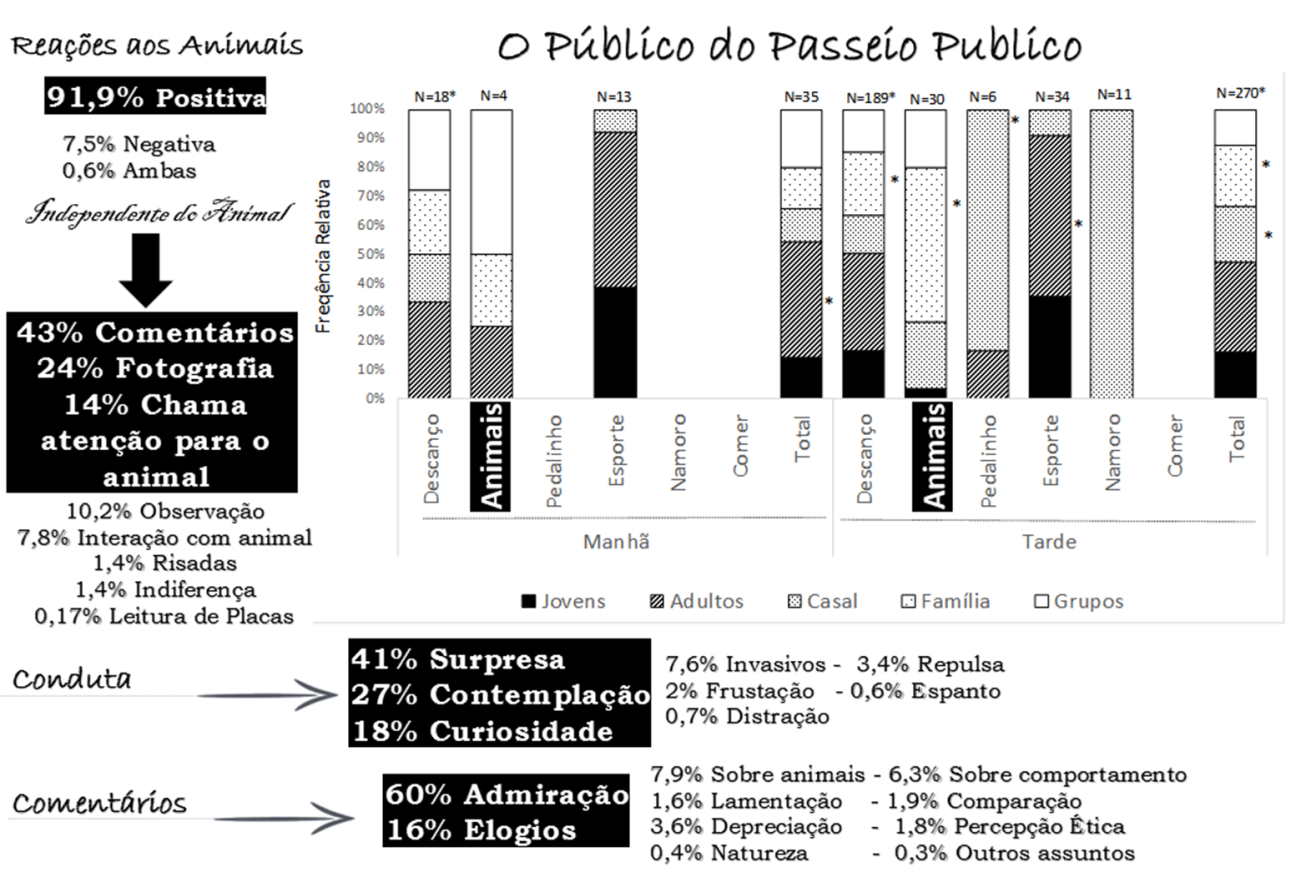

comentários

$\longrightarrow \begin{aligned} & 60 \% \text { Admiração } \\ & 16 \% \text { Elogios }\end{aligned}$
$3,6 \%$ Depreciação - $1,8 \%$ Percepção Êtica
$\begin{array}{ll}3,6 \% \text { Depreciação } & -1,8 \% \text { Percepção Etica } \\ 0,4 \% \text { Natureza } & -0,3 \% \text { Outros assuntos }\end{array}$

"Nossa que grande o pelicano!" - "Os macacos estão descansando!" - "Estão dormindo mãe?" - "Que diferente, cabelo arrepiado, parece o teu" - "Olha a tartaruga filha, que graça. Filha: ela ta escondida na casinha dela, né?" "Olha que querido, fica "comportadinho, Podemos ter em casa? Não filha, só se tivermos autorização" - "Olha que demais ele com as assas abertas! Já imaginaram ele voando? Que legal seria" - "Olha como o azul brilha com o sol (mulher para homem), lindo!" - "Essas pombas são um problema né? (falando com o tratador)" - "Criança chora que está indo embora e quer levar um pássaro com ela" "Por que será que elas estão correndo umas atrás das outras?" "A tartaruga não vive na agua?" - "Eles não gostam que batam no vidro!" - "Não é de verdade esse bicho, é muito bonito Parece que foi pintado esse bicho né? que incrivel" - "Nossa mais como é grande esse bicho, olha o porte dele que elegante!" - "É verdade que se o pavão olha pro pé ele morre!"

* A homogeneidade da amostra de categoria foi testada através do teste do Qui-quadrado, sendo os valores significativamente maiores $(P<0,05)$ apresentados na caixa escura.

ensino básico (Quadro 2). 0 morador de rua e a prostituta frequentam o Parque diariamente, e ambos apontaram a natureza e os animais como pontos positivos e bem-cuidados, por terem abrigo, alimentação diária, o que julgam necessário para atrair o público. A prostituta reclamou da alimentação, dos banheiros e principalmente da segurança, relatando ter sido assaltada, mas, ainda assim, considera um bom local para trabalho. 0 morador de rua disse que conversa com os animais e tem uma relação muito bonita com o Parque. 
Quadro 2 - Opinião de trabalhadores de Passeio Público

\begin{tabular}{|c|c|c|c|c|c|}
\hline & Funcionário & Policial & Vendedor & Pipoqueiro & Gerente \\
\hline Tempo de trabalho & 33 anos & 18 anos & 53 anos & 1 ano & 7 anos \\
\hline $\begin{array}{l}\text { Dificuldades } \\
\text { para trabalhar }\end{array}$ & $\begin{array}{l}\text { Falta material e } \\
\text { mão de obra }\end{array}$ & $\begin{array}{l}\text { População pede } \\
\text { ajuda e a lei veta }\end{array}$ & Mendigos & Clima/ Drogados & Prostitutas \\
\hline $\begin{array}{l}\text { Problemas } \\
\text { ambientais }\end{array}$ & Pombos & Lixo/urina no chão & Não há & Lixo & Não há \\
\hline $\begin{array}{l}\text { Problemas } \\
\text { segurança }\end{array}$ & Mendigos & Mendigos & Falta policial & $\begin{array}{l}\text { Falta policial/ } \\
\text { Mendigos }\end{array}$ & $\begin{array}{l}\text { Mendigos/ } \\
\text { Drogados }\end{array}$ \\
\hline Visitante & Caminhada & $\begin{array}{l}\text { Passear, brincar, } \\
\text { correr }\end{array}$ & $\begin{array}{l}\text { Passear, brincar, } \\
\text { correr }\end{array}$ & Usar drogas & Turista \\
\hline Piores dias & Sábado/domingo & Domingo & Terça/ sexta & Sábado/domingo & Domingo/terça \\
\hline Positivo & Animais & $\begin{array}{l}\text { Informações } \\
\text { turísticas }\end{array}$ & $\begin{array}{l}\text { Ambiente } \\
\text { agradável }\end{array}$ & Autonomia & $\begin{array}{l}\text { Ambiente } \\
\text { agradável }\end{array}$ \\
\hline $\begin{array}{l}0 \text { que poderia } \\
\text { ser mudado }\end{array}$ & Infraestrutura & Infraestrutura & Manutenção & $\begin{array}{l}\text { Manutenção / } \\
\text { Segurança }\end{array}$ & Segurança \\
\hline
\end{tabular}

\section{Discussão}

Os resultados da pesquisa possibilitaram caracterizar os usuários e os usos do Passeio Público, com a expectativa de subsidiar programas de revitalização do Parque, a fim de que a população disponha de um espaço democrático, seguro, com mitigação de vulnerabilidades, que possibilite a promoção de qualidade de vida e de saúde global.

Os respondentes evidenciaram usufruir da estrutura dos parques curitibanos revelando diversas referências a parques e usos, correspondendo à expectativa de que, diante da disponibilidade de espaço, há apropriação e atribuição de significados (Rodrigues, 1999). Curitiba vem ampliando os espaços públicos para preservação ambiental nos últimos 25 anos, as áreas verdes cresceram 50 vezes versus um aumento populacional de 2,4 vezes, resultando, em 2013, em 22 parques, 15 bosques, 454 praças e 12 reservas naturais, correspondentes a uma média de $58 \mathrm{~m}^{2}$ área verde/ habitante (IPPUC, 2013). Contudo, contrariando a expectativa de associação do espaço como uma busca pela natureza e com conceitos de sustentabilidade e conservação (Ferreira, 2005), os respondentes relacionaram tais espaços a uma função utilitarista, vinculando-os ao lazer e à prática de esportes destacando os parques mais populares e modernos, tais como Barigui, Jardim Botânico e Tingui. Esse resultado corrobora os dados de Dorigo e Ferreira (2015), porém, os autores, a parte do viés utilitarista, pontuaram que indiretamente há potencial para conscientização e educação ambiental para sustentabilidade, uma vez que minimizam os impactos ambientais, elevando a qualidade ambiental. Como exemplo, Dacanal, Labaki e Silva (2010) verificaram que 
os usuários de parques urbanos de Campinas foram hábeis em associar as áreas verdes ao conforto térmico e ambiental e vincularam sua presença à natureza. Os usuários do Jardim Botânico de Curitiba foram caracterizados, por Reis (2001), como predominantemente adultos de elevado poder econômico e intelectual que prezam por elementos tecnológicos e arquitetônicos e associam o espaço a valores e atitudes. Em geral são vizinhos dos parques e frequentemente usufruem de seu espaço para atividades físicas, majoritariamente caminhadas, caracterizando o uso de espaços próximos para o esporte, enquanto o lazer pode ser logrado em parques mais modernos e bem frequentados, mesmo que mais distantes. Deve-se considerar que grandes espaços verdes também podem comprometer a segurança almejada pela população, tendo em vista a menor densidade de usuários, as limitações para manutenção da limpeza, conservação e estrutura e potenciais formativos de nichos convidativos para cidadãos marginalizados, que podem causar desconforto para os usuários que buscam, nos parques urbanos, a experiência com a natureza, mas sem abrir mão da segurança associada às cidades (Dacanal, Labaki e Silva, 2010; Dorigo e Ferreira, 2015). Consequentemente, são enaltecidos os parques mais modernos e de localização que remeta a uma sensação maior de segurança e status social.

0 Passeio Público configurou-se como um espaço importante para a população curitibana, sendo associado, pela maioria dos respondentes, às lembranças da infância, mas de pouco interesse atual diante de suas deterioração e insegurança. 0 lazer e o zoológico, como os principais motivos para frequentá-lo, indicaram que, todavia, há receptividade.
A valoração esteve atrelada principalmente à localização, aos animais, à gama de atividades oferecidas e ao contato com a natureza. Esses dados legitimam a reincorporação desse espaço, importante na história e no cotidiano de Curitiba, uma vez que representa a concepção e os sentimentos a respeito dos espaços públicos intrinsicamente associados a informações, crenças, opiniões e atitudes (Moscovici, 1976). Os vínculos estabelecidos pelos frequentadores refletem um sentimento nostálgico acionado pelas memórias afetivas, representados por $37 \%$ de usuários que o associaram a lembranças da infância e a casos vivenciados com os animais. Segundo Lynch (1999), essa forma individual de relacionamento com a paisagem é agregada de elementos afetivos e topofílicos, oriundos de vínculos sujeito/paisagem, os quais para, Nora (1981) e Halbwachs (2003), constroem a memória coletiva, identidade e consequente sentido material, simbólico e funcional, constituindo-se em um ponto de destaque da presente pesquisa.

Os pontos negativos atribuídos por $85 \%$ dos respondentes referiram-se à conservação e aos frequentadores, identificados como marginalizados, viciados, prostitutas e mendigos, atrelando-os ao medo e ao constrangimento. Contudo, apenas $15 \%$ dos respondentes associaram a representação do espaço à lembrança negativa remetente a assaltos ou a constrangimentos. E, ainda, 23\% revelaram lamentação ou revolta diante da situação atual do Parque. Áreas segregadas e estigmatizadas são esperadas no processo de construção do espaço urbano (Vale e Maciel, 2016) e atribuições de significados, atreladas a diferenças sociais, crenças, valores e sentimentos, são muitas vezes negligenciadas pelas políticas urbanas (Corrêa, 
2003). Segundo Bauman (1999), a construção da modernidade ocorre sob o binômio ordem/ desordem; a ambiguidade inerente aos sujeitos com comportamentos desviantes e aos espaços que os abrigam é rejeitada, conduzindo à estigmatização territorial e à difamação dos espaços degradados (Goffman, 1988). Dessa forma, ao expressarem revolta, os respondentes demonstram que concebem os sujeitos indesejados como problema social a ser resolvido, conclamando intervenções efetivas. A insegurança expressa por muitos respondentes parece estar relacionada ao entorno, e não ao parque em si. A imagem da cidade, especialmente dos centros históricos, reforça os laços identitários e o sentimento de pertencimento, destacando-se os conflitos com questões éticas emergentes como a vulnerabilidade social (Pelegrini, 2006). Para Bauman (2009), as mesmas cidades que foram criadas para segurança atualmente despertam medo e insegurança, a desordem, o desconhecido e o incontrolável. A sociedade moderna é, então, caracterizada por relações fluidas, sem investimento emocional e de confiança, e o excesso de mobilidade, de responsabilidades, de informações reflete 0 sentimento agudo de insuficiência e banalização das experiências. Os espaços públicos atraem e desafiam, uma vez que podem ser locais vulneráveis a estranhos e perigosos, mas são únicos na superação e neutralização da rejeição devido ao inerente anonimato.

As concepções filosóficas e ambientais dos respondentes mostraram relação com idade, gênero e área profissional, e devem ser consideradas na gestão do Parque. As respostas dos idosos indicaram apropriação do espaço para bons momentos de lazer e socialização, provavelmente, remetendo a vínculos, referências e simbologias do passado nas quais o espaço se aliava à natureza disponível para préstimo antropocêntrico e utilitarista. Contrariamente, os jovens exibiram tendências biocêntricas e identificação com as condutas valorizadas pela sociedade contemporânea. As mulheres mostraram-se emotivas, mas cientes da realidade. Para elas, é importante a identificação de problemas para mobilizar suas resolução, a fim de que elas possam propiciar aos seus filhos suas experiências sem riscos que comprometam a saúde e o bem-estar (Bowlby, 2006). A perspectiva da psicologia ambiental interpreta esse padrão sob a lei do efeito de Thordike (Skinner, 2003), que preconiza a determinação das condutas presentes condicionadas a comportamentos bem-sucedidos no passado. Assim como através da teoria Life span (Neri, 1995), que propõe influência de uma variável normativa intermediada pelo contexto histórico cultural no desenvolvimento ontogenético. Nesse sentido, as diferenças de percepções estariam condicionadas às vivências. Por exemplo, os idosos de hoje se remetem a uma época que 0 animal era aceito como mero recurso e o Passeio Público era uma área de lazer. Já os jovens conectados, globalizados, bem-informados, autônomos, críticos e atualizados tenderam a ampliar a noção de mundo e de ser humano. As mulheres expressaram o vínculo com a maternidade e a utilização do espaço como promoção pedagógica e de vivências (Skinner, 2003). Essas diferenças, acrescidas daquelas identificadas entre os profissionais originários das áreas biológicas e não biológicas, são resultados que devem ser considerados em um plano de manejo do parque. Pois, mesmo com diversidade de aspirações e percepções, os grupos sociais têm direito e necessidade de 
usufruir de um espaço que promova bem-estar e aprimore sua qualidade de vida.

A percepção dos animais pelos respondentes do questionário on-line demonstrou a identificação de vulnerabilidades apenas por metade do grupo. Ainda assim, somente $9 \%$ deles relacionaram os maus-tratos como ponto negativo do parque, 33\% não souberam avaliar se os animais estavam bem e quais estavam melhores e piores, enquanto $28 \%$ afirmaram estarem bem. Tomas, Crompton e Scott (2003) e Clayton, Fraser e Saunders (2009), estudando o público de diferentes zoológicos norte-americanos, atestaram atraírem principalmente as famílias que buscam recreação, lazer e bons momentos com parentes e amigos. Segundo Tomas, Crompton e Scott (2003), cerca de 80\% dos visitantes dispõem de uma criança que conduz a visita, permanecendo cerca de 90 segundos diante de cada atração. Esses visitantes alegaram que a razão da visita foi os animais, logo não priorizaram a educação, considerando mais importantes os serviços, os estímulos interativos e a visualização de animais saudáveis em recintos próximos aos naturais. Tomas, Crompton e Scott (ibid.) e Fischer et al. (2017c) apontaram que a principal questão dos zoológicos é o conflito decorrente do interesse comercial. Morgan e Hadgkinson (1999) defendem a concepção de se constituírem como meio mais importante de contato entre pessoas/animais na sociedade moderna, porém deve ser atribuída responsabilidade dupla para as instituições, por beneficiar as pessoas e os animais, concordando com a inclusão da educação, porém sem prevalecer sobre a recreação, uma vez que esta é primordial para os visitantes.

A relação dos usuários do Passeio Público com os animais observados in loco foi positiva, predominando comentários de admiração e elogios, tomadas de fotografia e utilização do animal como motivador para interação com o interlocutor. Esses resultados correspondem com a análise de 1900 comentários de visitantes de zoológicos por Clayton, Fraser e Saunders (2009), em que o animal foi inserido no diálogo descritivo, direcionando-se para as crianças uma função pedagógica e as mulheres destacadas pela emotividade. Os autores identificaram experiência emocional, interação social e conexão, contudo não registraram reflexões sobre conservação, futuro do zoológico ou mudança de comportamento. Deve-se considerar que cerca de $10 \%$ dos usuários do Passeio Público ainda apresentaram atitudes negativas associadas a indiferença, repulsa, frustração e agressividade. Essa frequência correspondeu aos dados de Calyton et al. (2009), segundo os quais $9 \%$ dos visitantes direcionaram comentários negativos, devido ao gosto pessoal e à empatia ao invés de maldade. Segundo os autores, o público tende a apresentar uma ligação maior com a espécie do que com o animal individual, atribuindo à instituição a obrigação e a responsabilidade pela promoção de condições para alcançar o BEA. Ressalva-se que a baixa leitura de placas e a percepção ética nos comentários registradas no presente estudo foram identificadas pelos autores. Esses resultados remetem a estudos de Dierking et al. (2004) e Smith, Broad e Weiler (2008) que evidenciaram baixa adesão e resistência dos visitantes para atividades educativas, uma vez que a compreensão de questões de conservação trabalhadas na intervenção voltam ao estágio inicial após poucos meses. Segundo Smith, Broad e Weiler (ibid.), isso se deve ao distanciamento entre questões conservacionistas de realidade do visitante, 
sendo função da instituição selecionar e disseminar as mensagens mais efetivamente. $A$ presença de animais pode até motivar a participação na atração, como nos treinos abertos ao público, acrescidos de intervenção pedagógica, integrando recreação, educação, conservação e pesquisa, mas não motiva o aprendizado, 0 qual, segundo Cayton et al. (2008), só é alcançado em visitantes motivados a aprender.

A pesquisa identificou famílias com crianças como o público-alvo para apreciação dos animais, remetendo a função pedagógica, resgate emocional e incorporação da vivência na experiência social (Tomas, Crompton e Scott, 2003). Portanto, a mera retirada dos animais, no intuito de mitigar essa vulnerabilidade, pode incorrer no risco de descaracterização histórica, cultural e social desse espaço que representa uma memória afetiva aos curitibanos. Assim, enseja-se que se realize uma substituição planejada e intermediada, por uma equipe multidisciplinar, visando à promoção de entretenimento, lazer e educação, de forma que os visitantes se comprometam com a sustentabilidade e com condutas de respeito e cuidado com a natureza, o que pode ser alcançado por meio de técnicas tradicionais ou inovadoras.

Tradicionalmente, animais taxidermizados podem ser usados na substituição de indivíduos vivos (Taffarel, 2012). A oportunidade de contato com a morfologia real, somada à inserção em cenários naturais, acompanhados de estímulos sonoros, odoríferos, projeção de imagens em seu habitat e placas interativas, promove a uma experiência cognitiva real. Esses animais são obtidos de forma ética, ou seja, é dada uma utilidade para cadáveres de animais atropelados ou mortos naturalmente em cativeiros ou apreensões. 0 Jardim Sensitivo constitui-se igualmente uma alternativa para aguçar os sentidos, promovendo a experiência de sentir a textura e o aroma das plantas e estimular a interação e a apropriação da importância da interação com o ambiente e, ainda, possibilitando a inclusão social para pessoas com necessidades especiais (Borges e Paiva, 2009). A conexão com a educação é fundamental, principalmente com incorporação de jogos educativos e recreativos (Silva, Romani e Baranauskas, 2008) e estímulo às pesquisas de inovações que proporcionem os benefícios atrelados ao zoológico, porém sem os animais.

A substituição dos animais mantidos cativos em zoológicos tem sido atestada em alternativas tecnológicas, como documentários, projeções de filmes 3D/4D, usos de robôs, hologramas com imagens tão reais que parecem que podem ser tocadas e realidade virtual aumentada, promotora de experiência imersiva e interativa que se baseia em imagens gráficas $3 \mathrm{D}$ geradas por um computador em tempo real (Borges, 2011; Rodrigues e Porto, 2013, Silva e Marchi, 2015, Fischer et al., 2017b). Como exemplo, tem-se um Zoológico sem animais no Peru, que, por meio da realidade virtual aumentada, recria espécies selvagens em seu habitat, com todos os estímulos sensoriais correspondentes, oferecendo a interação com os animais e a natureza, com uma finalidade ética para a conservação da biodiversidade, do conhecimento científico, e com caráter educacional (Gestión, 2017). Parques temáticos têm investido em cenários de fantasias, interatividade, desafios e tecnologia, em que crianças, jovens e adultos se divertem e aprendem (Staudt e Cunha, 2016). 


\section{Considerações finais}

Os resultados elucidam a importância dos parques urbanos endossando a revitalização de espaços tradicionais, por meio da mitigação das vulnerabilidades, com intuito de democratizar os benefícios dos espaços públicos verdes para a saúde global dos cidadãos e do ambiente.

Os dados do presente estudo atestam que 0 adulto sem a companhia de crianças busca o parque urbano principalmente para lazer e prática de esportes, almejando um espaço bem-cuidado, tecnológico e livre de inconvenientes da vida natural e da presença constrangedora de pessoas marginalizadas. A família que possui crianças é mais adepta a parques que possuem atrações de entretenimento e que eventualmente possam servir para uma função pedagógica, legitimando a presença de animais. Os usuários percebem e apreciam segurança, conforto e estética, contudo os programas não devem se limitar à construção de espaços de lazer, mas prezar por uma ocupação mais ativa e democrática (Reis, 2001). Logo, a mera retirada dos animais poderia comprometer a história e a identidade de espaços históricos e entrepostos de valores e representações, como o Passeio Público. A maioria dos visitantes observados demonstrou satisfação em conviver com os animais, consubstanciando processos preconizados pela teoria da biofilia. Não se deve negligenciar as necessidades humanas, contudo deve-se considerar a vulnerabilidade dos animais diante do estresse do cativeiro. Logo a busca por soluções para equalizar essa questão é urgente; visões biocêntricas/ecocêntricas devem prevalecer aos consolidados referenciais antropocêntricos/utilitaristas. Embora os animais favoreçam a conexão no diálogo entre adultos, para as crianças essa situação se constitui a oportunidade de concretizar os símbolos utilizados em brinquedos e desenhos animados. Se, para o adulto não há motivação para autoeducação ao visitar um zoológico, para criança esse momento pode ser crucial na sua concepção do que é certo e errado na conduta com os animais. A incapacidade de percepção de um conflito ético entre interesses humanos e dos animais pode desestimular o adulto, direcionando, assim, as atividades educativas para as crianças.

A revitalização e a modernização do Passeio Público beneficiarão a sociedade e 0 ambiente. A gentrificação como parte mais abrangente da agenda social da reestruturação da economia e promotora de mudanças em uma sociedade de risco que se autoconfronta com os danos gerados pelo seu próprio desenvolvimento (Smith, 1996) demandando a construção de sujeitos-atores que atuem e pensem valores, conceitos e ações (Oliveira e Corona, 2008). Para Pacione (1990), é preciso estimular a mobilidade espacial de habitantes para voltarem a investir, ocupar e frequentar essas áreas, como é o caso do entorno do Passeio Público. Um ambiente urbano saudável é direito de todo cidadão brasileiro, assegurado pela Constituição Federal que condiciona, à política de desenvolvimento urbano, o objetivo de ordenar o pleno desenvolvimento das funções sociais da cidade e garantir o bem-estar de seus habitantes a partir do acesso ao patrimônio cultural e natural. Soma-se a isso o Estatuto da Cidade, lei 10.257/2001, que delega ao poder público municipal a garantia do bem-estar coletivo e cidades sustentáveis. 
Segundo Dorigo e Ferreira (2015), a percepção ambiental por parte da sociedade, do governo e de empresas apoia a gestão ambiental, uma vez que estimula a participação popular, que deve ultrapassar a representatividade em conselhos, assim como a intervenção do município por meio dos Planos Diretores (Pelegrini, 2006). A leitura da realidade social lapidada pela cultura, educação, temperamentos e percepções propicia a avaliação homem/natureza, direcionando pesquisas e intervenções na confluência de áreas como psicologia ambiental, geografia, ciências naturais e bioética. Diante de questões éticas complexas, plurais e globais, resultantes do intenso processo de industrialização, as ferramentas disponíveis não têm sido hábeis na intermediação do problema, o que pode ser mitigado pelo uso da bioética ambiental para a identificação dos agentes e pacientes morais e diminuição das vulnerabilidades identificadas por meio da promoção do diálogo e intermediação de soluções justas e consensuais apropriando-se da equalização dos valores. A institucionalização dessa ferramenta pode se dar através da constituição de Comitês de Bioética Ambiental aos moldes dos Comitês de Bioética Hospitalar e em Pesquisa com Animais e Humanos. De modo que, através dela, uma equipe multidisciplinar, composta por atores dos setores público e privado, representantes da sociedade e entidades de classe, congregue-se para avaliar propostas de pesquisa e intervenções em questões ambientais que envolvem a saúde global da população e da natureza.

[I] https://orcid.org/0000-0002-1885-0535

Pontifícia Universidade Católica do Paraná, Escola de Ciências da Vida, Programa de Pós-Graduação em Bioética. Curitiba, PR/Brasil

marta.fischer@outlook.com

[II] https://orcid.org/0000-0002-2679-7471

Pontifícia Universidade Católica do Paraná, Curso de Ciências Sociais, Escola de Educação e Humanidades, Programa de Pós-Graduação em Bioética e de Direitos Humanos e Políticas Públicas. Curitiba, PR/Brasil.

valquiria.renk@pucpr.br

[III] https://orcid.org/0000-0003-4778-4458

Pontifícia Universidade Católica do Paraná, Escola de Ciências da Vida, Departamento de Psicologia, Programa de Pós-Graduação em Bioética. Curitiba, PR/Brasil.

ana.moser@pucpr.br

[IV] https://orcid.org/ 0000-0002-1903-2163

Pontifícia Universidade Católica do Paraná, Escola de Ciências da Vida, Programa de Pós-Graduação em Bioética. Curitiba, PR/Brasil.

nati_taia21@hotmail.com 


\section{Agradecimentos}

Aos estagiários, alunos de ilniciação científica e mestrandos que ajudaram na coleta de dados: Mariane L. Rodrigues, Marina Kobai Farias, Camila Brito, Gabriela S. Rodrigues, Gabriele Vidolin, Gabriela Rodrigues e Augusto Paebano.

\section{Referências}

AUGUSTO, L. G. S. (2003). Saúde e vigilância ambiental: um tema em construção. Epidemiologia e Serviços de Saúde, v. 12, n. 4, pp. 177-187.

BARDIN, L. (2011). Análise de conteúdo. Lisboa, Edições 70.

BAUMAN, Z. (1999). Modernidade e ambivalência. Rio de Janeiro, Zahar. (2009). Confiança e medo na cidade. Rio de Janeiro, Zahar.

BOLETIM INFORMATIVO DA CASA ROMÁRIO MARTINS. (2001). Passeio público: primeiro parque público de Curitiba. Curitiba, Fundação Cultural de Curitiba, v. 28, n. 126.

BORGES, A. P. (2011). El holograma como fuente documental y recurso particular de información. Revista Española de Documentación Cientifica, v. 34, pp. 253-265.

BORGES, T. A. e PAIVA, S. R. (2009). Utilização do jardim sensorial como recurso didático. Revista Metáfora Educacional, n. 7, pp. 27-38.

BOWLBY, J. (2006). Formação e rompimento dos laços afetivos. São Paulo, Martins Fontes.

BRASIL (1988). Constituição da República Federativa do Brasil.

(1999). Política Nacional de Saúde Ambiental para o Setor Saúde. Secretaria de Políticas de Saúde. Brasília, Ministério da Saúde.

(2001). Lei n. 10.257, de 10 de julho de 2001. Estatuto da Cidade. Regulamenta os arts. 182 e 183 da Constituição federal, estabelece diretrizes gerais da política urbana e dá outras providências.

BRUN, F. G. K. et al. (2010). Percepção dos usuários em relação ao conforto ambiental de duas áreas verdes de Piracicaba, SP. REVSBAU, v. 5, n. 3, pp. 59-81.

CARLOS, A. F. A. (2007). O lugar no/do mundo. São Paulo, Labur Edições.

CERTEAU, M. (1996). A invenção do cotidiano. Artes de fazer, v. 1. Petrópolis, Vozes.

CLAYTON, S.; FRASER, J. e SAUNDERS, C. D. (2009). Zoo experiences: Conversations, connections, and concern for animals. Zoo Biology, v. 28, n. 5, pp. 377-397.

CORRÊA, R. L. (2003). “A geografia cultural e o urbano”. In: CORRÊA, R. L. Introdução à geografia cultural. Rio de Janeiro, Bertrand do Brasil. 
DACANAL, C.; LABAKI, L. C. e SILVA, T. M. L. (2010). Vamos passear na floresta! O conforto térmico em fragmentos florestais urbanos. Ambiente Construído, v. 10, n. 2, pp. 115-132.

DIERKING, L. D. et al. (2004). Using a behavior change model to document the impact of visits to Disney's Animal Kingdom: a study investigating intended conservation action. Curator: The Museum Journal, v. 47, n. 3, pp. 322-343.

DORIGO, T. A. e FERREIRA, A. P. N. L. (2015). Contribuições da percepção ambiental de frequentadores sobre praças e parques no Brasil (2009-2013): revisão bibliográfica. Revista de Gestão Ambiental e Sustentabilidade, v. 4, n.3, p. 31.

FERREIRA, A. D. (2005). Efeitos positivos gerados pelos parques urbanos. O caso do Passeio público da Cidade do Rio de Janeiro. Dissertação de Mestrado. Rio de Janeiro, Universidade Federal Fluminense.

FISCHER M. L. et al. (2017a). Da Ética Ambiental à Bioética Ambiental: antecedentes, trajetórias e perspectivas. História, ciência e Saúde-Manguinhos, v. 24, n. 2, pp. 391-409.

(2017b). Bioética Ambiental e Educação Ambiental: levantando a reflexão a partir da percepção. Revista Brasileira de Educação Ambiental, v. 12, n. 1, p. 58-84.

(2017c). Os Zoológicos sob a perspectiva da bioética ambiental: uma análise a partir do estudo de caso dos felídeos cativos. Revista Iberoamericana de Bioética, n. 4, pp. 1-17.

FORTES, P. A. C. e RIBEIRO, H. (2014). Saúde global em tempos de globalização. Saúde e Sociedade, v. 23, n. 2, pp. 366-375.

GARCIA, F. E. S. (1997). Cidade espetáculo. Política, planejamento e city marketing. Curitiba, Palavra.

GESTIÓN, el diário de economia y negócios de Perú (2017). EZoo, el zoológico sin animales. Disponível em: http://gestion.pe/tendencias/ezoo-zoologico-sin-animales-2160316. Acesso em: 1 jun 2017.

GOFFMAN, E. (1988). Stigma: notes on the management of spoiled identity. Rio de Janeiro, Guanabara.

GOLVEIA, N. (1999). Saúde e meio ambiente nas cidades: os desafios da saúde ambiental. Saúde e Sociedade, v. 8, n. 1, pp. 49-61.

GUILLÉN, D. M. G. (1991). Ecología y bioética. Madrid, Universidad Pontificia Comillas.

HALBWACHS, M. A. (2003). Memória coletiva. São Paulo, Centauro.

IPPUC - INSTITUTO DE PESQUISA E PLANEJAMENTO URBANO DE CURITIBA (2013). Curitiba em dados 2013. Disponível em: http://curitibaemdados.ippuc.org.br/. Acesso em: 25 mar

KELLERT, S. R. e WILSON, O. (ed.). (1993). The biophilia hypothesis. Washington, Island Press.

LYNCH, K. (1999). A imagem da cidade. São Paulo, Martins Fontes.

LOBODA, C. R. e ANGELIS, B. L. D. (2005). Áreas verdes Públicas Urbanas. Ambiência, v 1. n. 1, pp. 125-139.

MACEDO, S. S. e SAKATA, F. G. (2010). Parques urbanos no Brasil. São Paulo, Edusp.

MORGAN, M. e HODGKINSON, M. (1999). The motivation and social orientation of visitors attending a contemporary zoological park. Environment and behavior, v. 31, n. 2, pp. 227-239.

MOSCOVICl, S. (1976). A representação social da psicanálise. Rio de Janeiro, Zahar.

NERI, A. L. (1995). Psicologia do envelhecimento: uma área emergente. São Paulo, Papirus. 
NORA, P. (1981). Entre Memória e História: a problemática dos lugares. Projeto História: Revista de Estudos Pós-Graduados em História e do Departamento de História. São Paulo, v. 10, pp. 7-28.

OLIVEIRA, K. A. e CORONA, H. M. P. (2011). A percepção ambiental como ferramenta de propostas educativas e de políticas ambientais. Revista Científica ANAP Brasil, v. 1, n. 1, pp. 53-72.

PACIONE, M. (1990). Urban problems. An Applied Urban Analysis. Londres, Routledge.

PELEGRINI, S. C. A. (2006). Cultura e natureza: os desafios das práticas preservacionistas na esfera do patrimônio cultural e ambiental. Revista Brasileira de História, v. 26, n. 51, pp. 115-140.

POTTER, V. R. (2016). Bioética, ponte para o futuro. São Paulo, Loyola.

REIS, R. S. (2011). Determinantes ambientais para a realização de atividades físicas nos parques urbanos de Curitiba: uma abordagem sócio-ecológica da percepção dos usuários. Dissertação de Mestrado. Florianópolis, Universidade Federal de Santa Catarina.

RODRIGUES, A. B. (1999). Turismo e espaço. Rumo a um conhecimento transdisciplinar. São Paulo, Hucitec.

RODRIGUES, G. P. e PORTO, C. M. (2013). Realidade virtual: conceitos, evolução, dispositivos e aplicações. Interfaces Científicas - Educação, v. 1, n. 3, pp. 97-109.

SÁNCHEZ, F. (2013). A reinvenção das cidades para um mercado mundial. Chapecó, Argos.

SANTOS, M. (1988). Metamorfoses do espaço habitado. São Paulo, Hucitec.

SAUVÉ, L. (1996). Environmental education and sustainable development: a further appraisal. Canadian Journal of Environmental Education, v. 1, n. 1, pp. 7-34.

SILVA, V. A. e LORETO, M. D. S. (2011). Atenção primária ambiental e saúde da família: a necessidade da intersetorialidade. Serviço Social \& Realidade, v. 19, n. 1, pp. 91-124.

SILVA, F. B.; ROMANI, R. e BARANAUSKAS, M. (2008). SOO Brasileiro: aprendizagem e diversão no XO. Revista Brasileira de Informática na Educação, v. 16, n. 3, pp. 29-41.

SILVA, L. M. e MARCHI, P. M. A. (2015). Realidade aumentada como meio de atração e ampliação da experiência nos zoológicos de São Paulo. Revista de Iniciação Científica, Tecnológica e Artística, v. 5 , n. 4 , pp. 33-45.

SKINNER, B. F. (2003). Ciência e comportamento humano. São Paulo, Martins Fontes.

SMITH, N. (1996). The new urban frontier: gentrification and the revanchist city. Londres, Routledge.

SMITH, L.; BROAD, S. e WEILER, B. (2008). A closer examination of the impact of zoo visits on visitor behaviour. Journal of Sustainable Tourism, v. 16, n. 5, pp. 544-562.

STAUDT, V. F. e CUNHA, A. M. (2016). Parques temáticos como espaços de lazer e turismo: o caso do Alpen Park em Canela-RS. Revista Científica Digital-jornalismo, publicidade e turismo, v. 17, n. 1, pp. 111-131.

TAFFAREL, C. D. (2012). Museus escolares: a utilização de técnicas de taxidermia auxílio no ensino da educação ambiental. Revista de Monografias Ambientais, v. 10, n. 10, pp. 2128-2133.

TOMAS, S. R.; CROMPTON, J. L. e SCOTT, D. (2003). Assessing service quality and benefits sought among zoological park visitors. Journal of Park and Recreation Administration, v. 21, n. 2, pp. 105-124. 
TUAN, Y. (1980). Topofilia- Um estudo da percepção, atitudes e valores do meio ambiente. São Paulo, Difel.

VALE, C. S. V. e MACIEL, T. M. F. B. (2016). Áreas malditas: a estigmatização de espaços urbanos. Caderno de Geografia, v. 26, n. 45, pp. 255-267.

Texto recebido em 18/fev/2018

Texto aprovado em 6/abr/2018 